\title{
FAMILIAL JUVENILE DEGENERATION OF THE MACULA
}

\author{
BY \\ J. S. Steyn, M.D. \\ JOHANNESBURG, SOUTH AFRICA \\ LATE CHIEF ASSISTANT, UNIVERSITY EYE CLINIC, GRONINGEN. \\ (DIRECTOR: PROF. DR. G. F. ROCHAT)
}

ABOUT a year ago I examined a few cases of familial degeneration of the macula, in the University Eye Clinic, Groningen. This infrequent and peculiar disease is described under different names. Leber ${ }^{(1)}$ calls it "familiar-hereditäre Tapetoretinale Degeneration der Makulagegend," and C. Behr ${ }^{(2)}$ "Heredodegeneration der Macula." Batten ${ }^{(3)}$ described a form of cerebral degeneration associated with changes at the macula seen in several members of a childship.

The writer pointed out that though the clinical features and the ophthalmoscopic changes differ somewhat from those seen in the Waren Tay-Sachs disease, yet the pathological changes of the central nervous system, and the ganglion cells of the retina are so similar, that it seems probable that they are one and the same disease, but occurring at somewhat different periods of life. The children are born healthy and develop normally to a period of life varying with the different families. They begin to show, first, loss of intellectual faculties; then, loss of vision; and lastly, loss of motor power. The disease progresses slowly, eventually rendering the child blind, demented, and spastic. The disease is neither race nor sex selective. The changes at the macula consist of a diffuse pigmentation which extends more or less into the retina around. The disc is of a greyish-white colour, with vessels a little thinner than normal. I shall first describe the cases observed by me, and then compare them with the cases described by others.

Case 1.-T.W., aged 28 years, carpenter, came to the clinic in the beginning of 1923 with the complaint that his sight had gradually failed during the last three years, and that he was not able to perform his work as well as before. Previous to that time he could see well and had never had any trouble with his eyes. Patient was well built and otherwise healthy. The intellect was quite good. Urine : no albumen or sugar. Wassermann in blood negative.

The vision of the right eye was $6 / 36, \bar{c}+1, D$. Sph. 6/36. Vision of the left eye was $6 / 24 . \bar{c}+1,5 \mathrm{D}$. Sph.6/24, so that, though the patient was hypermetropic, glasses gave no improvement.

A year later the vision was O.D. 3/24, $\overline{\mathrm{c}}+1,5 \mathrm{D}$. Sph., $3 / 24$ and O S. $3 / 18$ partly, $\bar{c}+1,5 \mathrm{D}$. Sph., 3/12. The fields of vision were 
not contracted, but he had central scotomas for colours. The patient was not colour blind. The pupils were round and reacted well to light and convergence. The movements of the eyes were free in all directions. Examination of the anterior parts of the eyes revealed no changes.

The papillae were slightly on the pale side, but had well defined borders. The arteries were slightly thinner than normal.

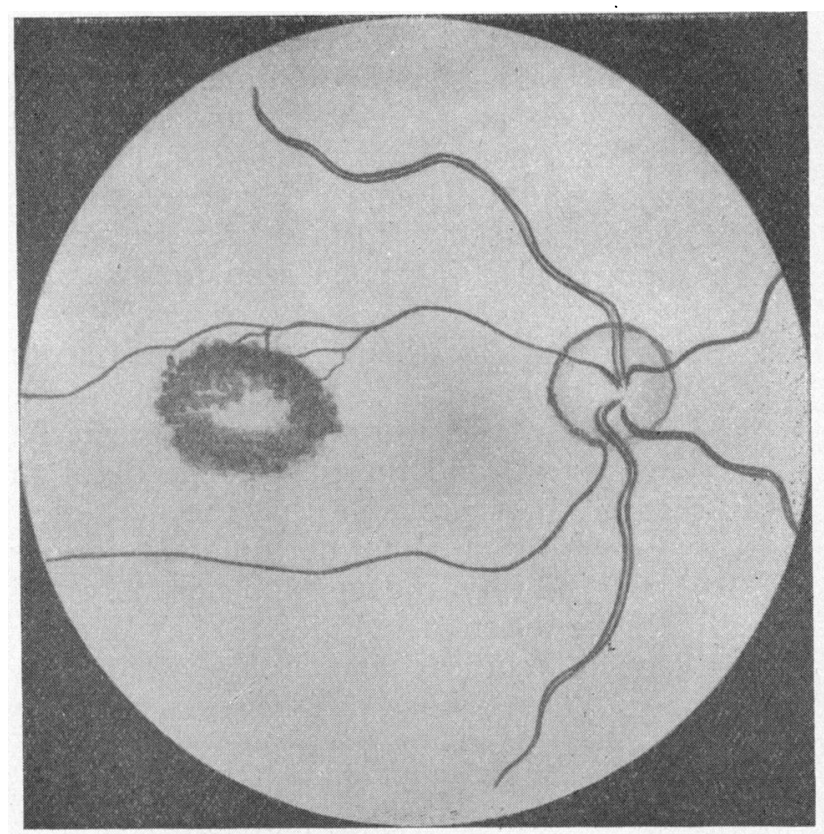

At the macular region was a diffuse pigmentation forming an oval-shaped body, a little larger than the disc, with compact pigment on the border, more granular towards the centre, in which was a little white spot.

In the remaining parts of the fundus no abnormalities were found. The changes in the left eye were exactly like those of the right eye, except that the central white spot in the pigmented area was a little smaller than that of the right eye.

Case 2.-P.W., aged 21 years, carpenter (younger brother of T.W.), came to the clinic in 1922 with a foreign body on the cornea of the left eye. He further stated that he had seen little or nothing with the right eye for the last two years. Before that time he did not notice that his sight was bad. Patient was well built and healthy. Urine : no albumen or sugar. On examination 
a foreign body was seen on the cornea of the left eye 2 or $3 \mathrm{~mm}$. from the upper margin of the limbus with a slight infiltration round it. The pupillary region of the cornea was free. The vision of the eye was $6 / 12$ partly, $\overline{\mathrm{c}}+1 \mathrm{D}$.Sph., $6 / 12$. The foreign body was removed and a month later when the cornea was quite normal again the vision was still $6 / 12$ and could not be improved.

The vision of the right eye was $4 / 60$ and could not be improved with glasses, although the patient was found to be hypermetropic $3 \mathrm{D}$. in the eye. The field of vision of the right eye was found to be slightly contracted, especially on the temporal side, and there was a central scotoma for colours.

Movements of the eye were free in all directions and the pupil reacted normally to light and convergence. Ophthalmoscopic examination revealed no changes in the anterior parts of the eye. The disc was slightly pale and the arteries rather thin. At the macula the same changes were found as described in the first case.

The family history of the two patients is as follows: The grandfather and grandmother on the father's side could see well; but the father and his only sister have very bad eyesight. My two patients have another brother and sister, the brother sees very badly, while the sister has normal eyesight. Unfortunately they could not be examined.

A third case of which I would like to give a short account is a girl, aged 13 years. She came to the clinic for the first time in 1921 , when she was ten years of age, with the history that her sight had been gradually getting worse during the last three years. Before that time she could see well (I was informed by the parents). The vision of both eyes was then $5 / 60$ and could not be improved with glasses.

The girl was otherwise physically quite normal. Urine: no albumen or sugar. Wassermann was negative. Since 1921 the vision has gradually got worse so that she has at present a vision of $1 / 300$ of the right eye and $2 / 60$ of the left eye. The anterior parts of the eyes were found to be quite normal. The papillae were rather pale and the vessels thin; while the maculae were diffusely pigmented with granular pigment, a small white spot being in the centre of the pigmented area.

It is thus seen that in the case of two brothers the disease started at the age of about 20 years, while in the case of the girl it started at the age of six to seven years; this is in accordance with C. Behr's description that in each family the disease has a typical time of appearance and course. It always affects the members of any one family at the same time of life, either at the age of six to eight years (Behr's infantile group) or at the age of 14 to 20 years (Behr's adult group) The disease is mostly either progressive, but never leads to total blindness unless there is a 
simultaneous severe complication, as optic atrophy, or becomes stationary after some time, and sometimes improves.

According to Alkio, who described four cases of hereditary macular degeneration in one family, which cases correspond very much with mine, colour blindness was a very prominent symptom. This symptom was also observed in ten other cases by Best, Nettleship, Nagel, Uhthoff, Hess, Grunert, and Behr, cit. Alkio.

In my cases colour blindness was absent, but they all had central scotomas for colours. Leber places the pigment degeneration of the retina in one great group and subdivides it into :

(1) The typical retinitis pigmentosa.

(2) Special forms of pigment degeneration of the retina with its analogous diseases to which group belongs the familial tapetoretinal degeneration of the macula and papillary region. Near to this group stands the Waren Tay-Sachs family amaurotic idiocy. Leber called it tapeto-retinal degeneration as the disease starts in the pigment epithelium (tapetum nigrum), and afterwards spreads to the other layers of the retina. K. Stargardt, however, divides the pigment degenerations of the retina into four groups :

(1) "Die familiare präsenile" macular degeneration (Tay) or choroiditis guttata.

(2) “Die familiare honigwabenähnliche” macular degeneration (Doyne).

(3) “I)ie familiare angeborene" macular degeneration (Best).

(4) "Die familiare progressioe" macular degeneration $(a)$ with and $(b)$ without psychical disturbances.

The cases described by me fall under group four of Stargardt, while the first two cases fall under (1) and the last one under ( 2$)$; because the two brothers T.W. and P.W. were quite sound in mind while the young girl manifested symptoms of dementia. She walked about in her sleep and would sometimes laugh for quite half an hour without any apparent cause, which is certainly striking in a girl who is almost blind. She sometimes stood on her head in bed, climbed on the cupboards in the ward and did other things suggestive of idiocy.

This young girl in whom the disease started at the age of seven comes under Behr's infantile group, while the two brothers, where the disease started at the age of twenty years, fall under his adult group. We further notice that the disease progresses very slowly in the case of the brothers where it started at the age of twenty, while in the case of the girl where it started at seven, it had a very rapid course, as she is almost blind at the age of 13 years. This 
is in agreement with Batten's statement that the later in life the disease appears, the less acute the course seems to be, and in those cases in which the visual defect manifests itself during or after the second decade of life, there appears to be little or no liability for the central nervous system to be affected.

\section{REFERENCES}

1. Leber.-Graefe-Saemisch Handbuch, p. 1204-11, 1915.

2. Behr.-Die Heredodegeneration der Makula.Klin. Monatsbl. f. Augenheilk., Bd. 65, ss 265-505, 1920.

3. Batten.-Brit. Jl. of Ophthal., 1921.

4. Alkio.-Actu Ophthal., Vol. 1, p 27.

5. Stargardt.-Ueber familiare Degeneration in der Makulagegend des Auges mit und ohne psychische Störungen. Arch. f. Psychiatrie, Bd. 58, ss. $852-87,1917$.

\section{ANNOTATION}

\section{Pedigrees}

It was Juvenal, so far as we know, who first threw cold water upon genealogy. Stemmata quid faciunt: of what use are pedigrees? He was speaking of the absurdity of trying to derive all and sundry from noble blood; and in this connection it is worth while reminding our readers that one of the greatest genealogists of all time has written on this subject as follows :*

"It is not always that the generations of a family, of mere knightly degree, can be traced with certainty up to the beginning of the thirteenth century. The latter half of the twelfth century is, in similar investigations, a limit not often surpassed with probable truth, whilst its earlier half is only a field for the wildest conjecture."

In dealing with the genealogy of disease, we must remember that it is very unusual to find more than four generations in any family, alive at the same time. We do not think that it would be possible for a surgeon to examine more than four generations of any family with regard to the eyes. In this matter of pedigrees of disease we are building for our successors; and so long as no attempt is made to trace eye disease in families back to mediaeval times, the pedigrees which are now being drawn up and carefully recorded, such as those published in this number and those recorded in the monograph on colour blindness, will be of the greatest value in years to come. 